\title{
EL BARRIO DE SAN BERNARDO (SEVILLA)
}

Angel L. VERA ARANDA*

\section{INTRODUCCION}

Dentro de las múltiples formas en que puede realizarse el estudio de la ciudad, la segmentación de la misma en pequeñas unidades de características homogeneas es, quizás, la que posibilita un conocimiento mas detallado de todos sus elementos. Además es la forma más rigurosa de sentar las bases para un posterior análisis global que permita conocer mejor el fenómeno urbano.

El presente trabajo aborda el estudio de una de estas unidades: el barrio de San Bernardo, como parte integrante de la trama urbana de Sevilla. Aquel aparece como el paradigma de una de las tres grandes áreas que componen la ciudad: la orla pericentral en torno al casco antiguo.

La orla pericentral sevillana está formada por una serie de arrabales históricamente situados extramuros, entre los que caben mencionar: Triana (el principal), el propio San Bernardo, La Calzada, Trinidad, La Barzola, etc.

Las características de la orla quedan perfectamente reflejadas en el caso de la zona estudiada. Area aislada de la ciudad hasta el siglo pasado, pasa a integrarse en la misma tras el derribo de la muralla (1860-70), para, de nuevo recientemente, volver a quedar inconexa, debido al espectacular crecimiento de la urbe, que la sobrepasa y se «olvida» de ella, centrando su interés o bien en el centro urbano, por el comercio y los servicios, o bien en la periferia como lugar de residencia y de actividad industrial.

Lo más llamativo del caso es que esta zona casi abandonada en la actualidad, ha pasado a ser practicamente el centro geométrico de Sevilla. Sus límites quedan establecidos por la Avenida de Eduardo Dato por el Oeste; el muro de separación con la Huerta del Rey por el Sur; la Avenida de Ramón y Cajal por el Este, y el complejo de la estación de ferrocarril de Cádiz y las vías férreas por el Norte.

(*) Catedrático de Ens. Media en Geografía e Historia. Priego, Córdoba. 
San Bernardo engloba por tanto no sólo su núcleo tradicional sino tambiér su expansión a partir del siglo XIX, en el área entre la calle Campamento : la Huerta del Rey hasta la actual Facultad de Ciencias Económicas y Empre sariales. La superficie que ocupa es de unos $130.000 \mathrm{~m}^{2}$ aproximadamente; dis tando entre 300 y $400 \mathrm{~m}$. de la Puerta de la Carne (lugar de acceso a la ciudac en el antiguo recinto amurallado).

\section{APROXIMACION HISTORICA}

Las primeras noticias que tenemos de San Bernardo se remontan a époc: musulmana, cuando la zona empieza a poblarse en el tránsito del siglo XI a XII, formándose el arrabal de Benaliofar. Sus habitantes viven al amparo de palacio, los jardines y el cultivo hortícola de la muy próxima Buhayra. Lo: escasos testimonios hacen referencia al carácter agrícola de sus pobladores ! a una cierta importancia del arrabal en cuestión.

La conquista de Sevilla por las tropas cristianas del Rey Fernando III, con lleva el que previamente sean destruidas todas las edificaciones que no se en cuentran protegidas tras la muralla. De esta forma, en 1247 es totalmente arra sado Benaliofar, del que sólo queda una pequeña ermita que el Rey Santc dedica a San Bernardo, onomástica del día en que se tomó la ciudad.

La Baja Edad Media supuso una casi total despoblación del área. La Bu hayra queda convertida en la Huerta del Rey, y se inicia una dura pugna po] la posesión de los terrenos entre la Monarquía (Juan II, Enrique IV, etc.) I la nobleza (Alvaro de Luna, Juan Monsalve, etc.) que se resuelve a fine: del siglo XV, cuando los Reyes Católicos otorgan la propiedad a Catalina de Ribera.

Por ésta época, se inicia la reconstrucción del barrio, gracias a la explotaciór de las tierras para la agricultura (fundamentalmente por Moriscos), y la cons trucción del primitivo matadero y el convento de Portacoeli. Las crónicas tam bién hablan de una intensificación de los cultivos por el regadío.

El siglo XVI es un período de fuerte crecimiento en todos los sentidos, pa ralelo al que experimentó la metrópoli hispalense. Andrea Navaggiero y Orti: de Zúniga nos han legado sendas descripciones en las que hacen patente lé importancia de San Bernardo, unida, no sólo a su tradicional riqueza agrícola sino a la creciente aparición de industrias que buscaban terrenos extramuro: para desarrollar las actividades peligrosas. Así aparecen numerosos hornos de pan, y desde 1565 se establecen la fundición de Juan Morel, precedente lejanc de la actual fábrica de Artilleria. A fines de siglo se erige en consonancia cor el crecimiento del barrio, el primer templo parroquial. 
San Bernardo ha seguido durante toda su historia una evolución parecida a la de Sevilla. Así durante el siglo XVII se produce una fuerte crisis que también afecta a todos los ordenes: económico, social, demográfico, etc. Esta crisis alcanza su punto álgido durante la epidemia de peste de 1649 que despuebla la zona, reduciendo su población a casi la mitad. Los últimos cincuenta años del siglo experimentan una ligera recuperación, aunque se mantiene el tono de decadencia propio de la centuria del Barroco.

De nuevo se invierte la tendencia a partir del XVIII, pues salvo pequeños períodos, a este siglo corresponde un nuevo momento expansivo, con aumento de los rendimientos agrícolas gracias a las buenas cosechas de la primera mitad de siglo, y a la construcción en 1782 de la fábrica de Artillería, que consolidó la función industrial de San Bernardo. De 1785 data la actual iglesia Parroquial. La importante actividad constructiva se ve frenada desde finales del siglo XVIII y principios del siguiente a consecuencia de la aparición de fuertes epidemias de fiebre amarilla. El deficiente estado higiénico-sanitario del barrio motivado entre otras causas por la presencia del matadero, cuyos desechos eran arrojados al ya de por sí insalubre arroyo Tagarete, unido al bajo nivel económico de sus habitantes, hacen que sea proclive al ataque de la epidemias, que se ceban sobre el lugar durante el primer tercio del XIX.

La segunda mitad del XIX y los principios del siglo XX, suponen, indiscutiblemente, la mayor transformación de San Bernardo en toda su historia. Se sitúan en él numerosas industrias: La pirotecnia militar, la fábrica de cápsulas, el nuevo matadero, etc. Se realizan numerosas obras públicas para mejorar la zona: cubrimiento del arroyo Tagarete, derribo de la muralla, construcción de los pasos elevados de San Bernardo y la Enramadilla para salvar la vía ferroviaria. Pero sobre todo, el mayor acontecimiento de una gran repercusión, fue la inauguración de la estación de ferrocarril en 1860, que, si bien incrementaba la importancia de San Bernardo por lo que representa de actividad económica, también cercenaba de modo decisivo la relación entre el barrio y Sevilla, separando radicalmente a ambos y aislandolo en gran medida de su crecimiento posterior.

El siglo XX supone el apogeo y el ocaso a la vez para San Bernardo (hacia la mitad del siglo se produce el máximo auge, y se inicia de inmediato la decadencia). El primero unido a las características que en el XIX hicieron del barrio una zona industrial, desterraron la actividad agrícola y atrayeron población gracias a las numerosas fábricas instaladas en el mismo. El ocaso motivado en los últimos 30-40 años por una serie de circunstancias desgraciadas ajenas al propio barrio: envejecimiento de las edificaciones, no renovadas a consecuencia de las ordenanzas de la legislación urbanística; oferta de viviendas 
en el extrarradio de la ciudad en mejores condiciones; aislamiento geográficr del barrio, causado por el propio crecimiento de la ciudad; todo ello unido : la desastrosa riada del Tamarguillo (1961), viene a ocasionar la degradació y el abandono de San Bernardo.

\section{EVOLUCION DE LA POBLACION ENTRE LOS SIGLOS XVI Y XX}

Para este estudio nos hemos basado en tres fuentes: Registro del númerc de bautismos, matrimonios y defunciones anotados en los libros del archivi parroquial; censos, padrones y recuentos de población y, en tercer lugar, toda aquellas citas bibliográficas de diversos autores (Ruth Pyke, Leandro José di Flores, Doctor Vera, etc.) y muy distintas procedencias que aporten datos di interés.

No es posible iniciar esta investigación antes del siglo XVI pues los dato: de época musulmana o bajo medieval son muy incompletos y escasamente fia bles. El punto de partida hay que situarlo en el inicio de las series parroquiale: en 1558 que se conservan con continuidad a partir de 1570 . Se deduce en estr primer momento un volumen considerable de población, en crecimiento hast: finales de este siglo, motivado por la llegada de elementos procedentes de exterior, gracias a la buena coyuntura económica. Del número de nacimiento: y defunciones, y del estudio de vecinos por collaciones según los recuentos dt la época, podemos estimar en torno a dos mil el número de pobladores de li parroquia a fines del siglo XVI.

Ya hicimos mención en el apartado anterior a la hecatombe que supuso par: la población sevillana la epidemia de peste de 1649. Evidetemente, la repercu sión sobre San Bernardo fue similar a la de la urbe. Bien es cierto que de estudio de los datos del archivo se deduce una clara tendencia al estancamien to e incluso a la recesión desde finales del siglo anterior (primeras epidemias. y comienzos del XVII (expulsión de elementos moriscos hacia 1610, comuni dad de cierta importancia en el barrio).

La crisis de 1649 merecería por sí sola un artículo dada la abundancia de datos existentes. En este caso nos limitaremos a comentar su importancia. La: cifras son muy significativas: El número de muertos registrados entre Mayo ! Junio fue de 404 aunque el párroco hizo constar que, al menos, otra cifra si milar se dió entre aquellos afectados que murieron en Hospitales fuera de barrio y que por tanto no fueron recogidos. Puede estimarse en cerca de 1.00( el número total de fallecidos en dicho año. La población descendió de algc menos de 2.000 personas en 1648 , a poco más de 1.000 en 1650 . Los efecto: a la vista de tales datos huelga comentarlos. 
Durante la segunda mitad del XVII, cambia la tendencia. La despoblación sirve para paliar en cierta medida, la crisis económica, y se inicia un ligero aumento de población a finales de siglo, que va creciendo paulatinamente hasta que durante la primera mitad del XVIII se transforma en lo que podemos calificar de auténtica «explosión demográfica», aunque este término haya que ponderarlo en su justa medida.

Sin duda el período 1700-1750 fue de recuperación, todos los índices muestran esta característica. Coadyuvan a ella, como ya se dijo, la climatología y las cosechas; sólo se producen pequeñas crisis puntuales a consecuencia de algunas epidemias (en 1708, por ejemplo), que no modifican la línea ascendente de la población.

La prosperidad se mantiene hasta finales del siglo XVIII, con algunos pequeños momentos de crecimiento lento, como el decenio de 1750 a 1760 , pero sin grandes altibajos por regla general. Del buen momento a que hacemos referencia nos dan idea la construcción de la nueva fábrica de Artillería (una de las más importantes de Europa) y la ampliación del templo parroquial (señal indudable del crecimiento de la población y de una coyuntura económica favorable).

San Bernardo ha oscilado a lo largo de su historia entre dos polos opuestos: por un lado, el idílico vergel que suponía la Huerta del Rey, reflejado por los viajeros que lo visitaron (Navaggiero, Zuñiga, etc.); por otro, el pestilente Tagarete, que arrastraba parte de la inmundicia de la ciudad, además de ser el lugar donde se vertían los despojos del matadero. La perjudicial influencia de éste queda señalada por distintos autores (Dr. Vera, 1793; Dr. Hauser, 1884) quienes subrayan las repercusiones negativas que tenía como foco de insalubridad y de infecciones, lo que unido a unas condiciones de vida bastante difíciles, debido al bajo nivel económico de la mayor parte de los habitantes del barrio, hacía a éste foco propicio para el surgimiento de epidemias y la aparición de una mortalidad catastrófica. Ejemplo son las fuertes epidemias de fiebre amarilla y cólera que sufre la población durante la primera mitad del XIX, pudiéndose calcular en este período su fuerte descenso de casi 3.500 habitantes a poco más de 2.500 medio siglo después. Hay otros hechos (invasión francesa, riadas, malas cosechas, etc.) que completan el desolador panorama que ofrecen los comienzos del pasado siglo.

Desde $1840-50$, se produce una nueva etapa con características muy positivas para el crecimiento. Hay que volver a hacer referencia a los acontecimientos históricos antes mencionados para comprender el porqué de este auge. Indiscutiblemente unido a este avance económico, hay que señalar otros hechos 
de carácter general: mejora higiénica y sanitaria (desaparición del Tagarete mayor control sobre el matadero, agua y alcantarillado, limpieza municipal etc.), lo que redunda en un importante crecimiento vegetativo de la población observable a todos los niveles. Por otra parte se produce una fuerte inmigra ción de los pueblos a la capital. Los inmigrantes se asientan en gran númerı en San Bernardo, atraídos por la demanda de mano de obra para la industri próxima y el ferrocarril, y por la oferta de vivienda barata en las afueras de casco antiguo.

Esta tendencia se incrementa durante la primera mitad del presente siglo con sólo un breve intervalo de estancamiento en la transición de un siglo : otro. Aunque este crecimiento es debido, en parte, a la afluencia de poblaciós foránea (apogeo entre 1910 y 1930) como consecuencia de las obras para li exposición Iberoamericana de 1929, la característica más destacada del mismı es el crecimiento natural de la población, una vez que se ha controlado la fuer te mortalidad, manteniéndose por el contrario una altísima tasa de natalidad

En los años intermedios de este siglo, San Bernardo presenta un panoram: demográfico caracterizado por el mayor número de habitantes de toda su his toria, lo que a su vez provoca su hacinamiento: Unos 6.000 habitantes, mien tras que el espacio urbano había dejado de crecer hacia 1910-15, con la crea cñión de la calle Barrau y la colmatación del terreno existente al final de li calle Campamento. En el período 1910-50, la población pasó de los 4.500 : los 6.000 habitantes antes mencionados.

Las últimas cuatro décadas han supuesto la mayor degradación del barric en toda su historia, y uno de los ejemplos más lamentables existentes en cuan to a abandono y ruina de la ciudad tradicional, tal y como se refleja much más ampliamente en el siguiente apartado. La población ha pasado de 6.08: habitantes en 1950 a sólo 913 en 1986. Las causas ya han sido apuntadas, ! sobre ellas volveremos nuevamente: Envejecimiento del edificado, mejor ofer ta de vivienda en otras áreas, política urbanística negativa, mejora de las con diciones del nivel de vida de la población, aislamiento del barrio, etc.

A principios de la presente década se vive el momento más crítico de st existencia. Las casas ruinosas se convierten en refugio de gitanos y vagabun dos, la mayor parte de las edificaciones amenazan con caerse, hay calles que se despueblan totalmente. La situación es denigrante. Recientemente la Coo. perativa de viviendas inicia por fin la construcción de nuevos edificios que de ben marcar la pauta de la recuperación de la zona; recuperación a la que s€ unen las grandes reformas que el nuevo PGOU propone a la Sevilla que s€ prepara para la Exposición de 1992. 


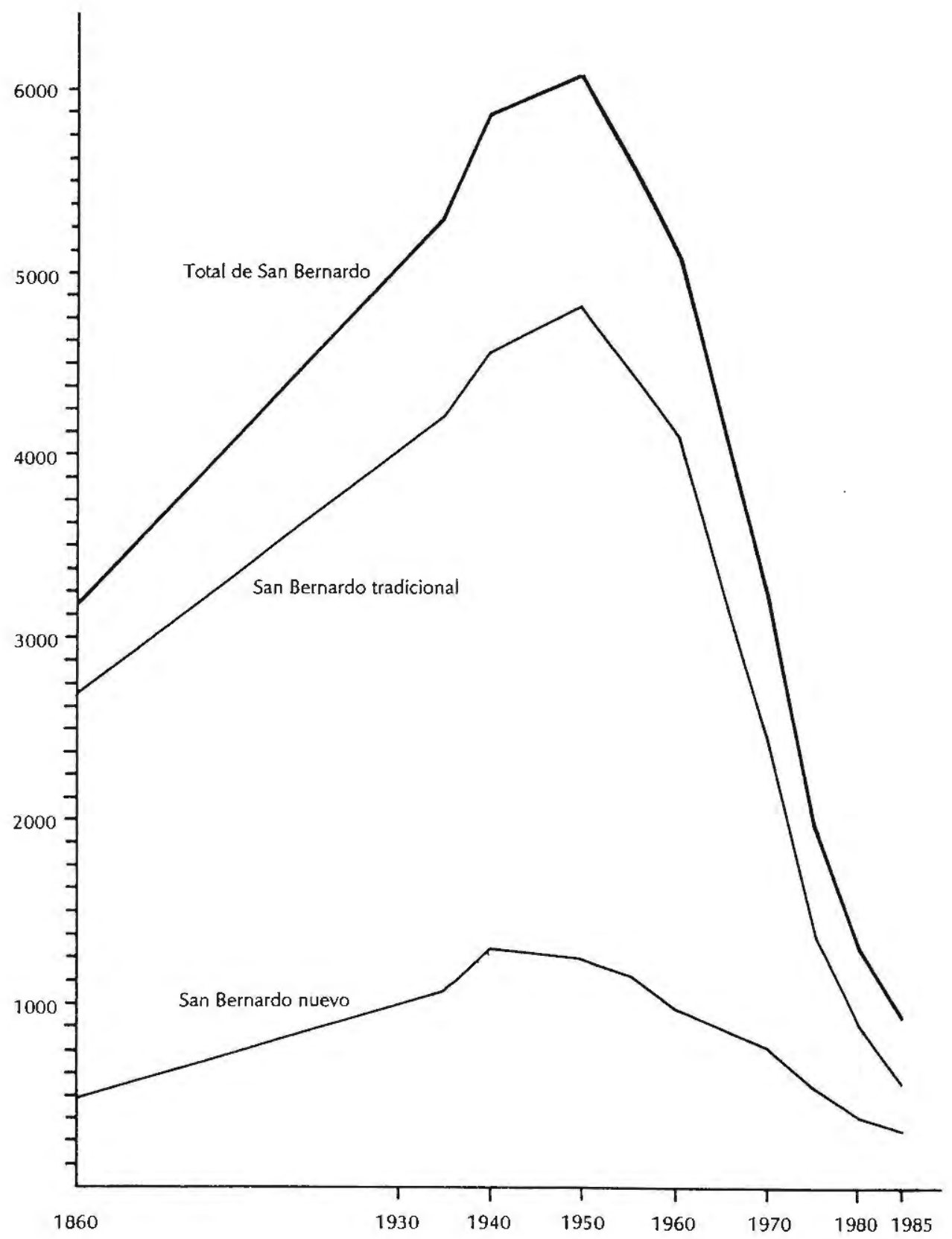

Población de San Bernardo, 1860-1985, total y por zonas. 


\section{ESTUDIO DEMOGRAFICO DE LOS ULTIMOS RECUENTOS PADRONALES}

Este medio siglo es el momento en que se produce el apogeo y el decliv demográfico de San Bernardo, ello determina que sea este período central e nuestro estudio.

Analizando las estructuras de la población podemos llegar, en parte, conocer los motivos por los que se produce este fortísimo descenso.

El recuento de los padrones arroja las cifras que se observan en el Cuadro I

\section{CUADRO I}

\begin{tabular}{|c|c|c|c|c|c|}
\hline Año & Habitantes & $\begin{array}{l}\text { Variación } \\
\text { absoluta }\end{array}$ & $\begin{array}{l}\text { Icremento } \\
\text { anual } \\
\text { absoluto }\end{array}$ & $\begin{array}{l}\text { Incremento } \\
\text { anual } \\
\text { relativo }\end{array}$ & $\begin{array}{l}\text { Indice } \\
\text { de } \\
\text { crecimiento }\end{array}$ \\
\hline $1935 \quad \ldots \ldots \ldots \ldots \ldots \ldots \ldots \ldots$ & 5.291 & - & - & - & 100,00 \\
\hline 1940 & 5.869 & 578 & 115,6 & 1,09 & 110,92 \\
\hline $1945\left(^{*}\right) \quad \ldots \ldots \ldots \ldots \ldots \ldots$ & - & - & - & - & - \\
\hline 1950 …… & 6.083 & 214 & 21,4 & 0,36 & 114,97 \\
\hline 1955 & 5.643 & 440 & 88,0 & $-1,45$ & 106,65 \\
\hline 1960 & 5.094 & -549 & $-109,8$ & $-1,95$ & 96,28 \\
\hline 1965 & 4.192 & -902 & $-180,4$ & $-3,54$ & 79,23 \\
\hline 1970 & 3.216 & -976 & $-195,2$ & $-4,66$ & 60,78 \\
\hline 1975 , & 1.978 & -1.238 & $-247,6$ & $-7,70$ & 37,38 \\
\hline 1981 , & 1.313 & -665 & $-133,0$ & $-6,40$ & 24,82 \\
\hline 1986 & 913 & -400 & $-80,0$ & $-6,09$ & 17,26 \\
\hline
\end{tabular}

(*) Este padrón no se halla disponible en la Delegación Municipal de Estadística.

La falta de los datos del padrón de 1945 nos impide conocer con exactitur cuál ha sido el momento en que se ha alcanzado el máximo de población, perı la recta de tendencia nos induce a situarlo a fines de los años 40, hacia 1948 49. Desde ese momento el descenso ha sido continuo y casi constante, acele rándose algo más a partir de 1960 (recuérdense los desastrosos efectos de 1: inundación del Tamarguillo en 1961). El punto álgido de la emigración se lo caliza en el quinquenio 1970-75 y se ralentiza a partir de ese momento, nc tanto por el hecho de que disminuyan el número de salidas, sino porque e bajo nivel de población impide que pueda seguir existiendo esa emigración e1 el mismo volumen que antes. 


\section{LA ESTRUCTURA DEMOGRAFICA POR SEXOS Y EDADES}

Un breve análisis de las pirámides de población de 1935 y de 1986 permite conocer cómo ha repercutido este proceso de despoblación sobre San Bernardo.

En 1935, la pirámide presenta una población muy joven, aunque se observa un cierto envejecimiento por la base. Esto, que puede parecer un tanto anómalo, no es realmente así ya que se trata de una pirámide engrosada en sus estratos intermedios por el aporte de población inmigrante entre los 20 y los 34 años. Por otra parte, la posible reducción de la natalidad se corrige en las pirámides de 1940 y 50, aquí no representadas. El resto de la pirámide responde a las características de una población muy joven, estrechándose por la altura, a consecuencia del escaso número de ancianos existentes.

La pirámide de 1986, por el contrario, nos muestra una población muy envejecida, tanto por la base como, sobre todo, por la altura, resultando el grupo más numeroso el de los 70 a los 74 años, y principalmente, en el sexo femenino, como es frecuente en estas edades. Es también muy significativo el hecho del estrechamiento en los estratos intermedios correspondientes a los adultos, en concreto los grupos entre 30 y 44 años que son los menos numerosos en efectivos de todos.

Hay que resaltar, pues, el cambio cualitativo de una población joven en 1935 a una población muy envejecida en 1986, debido a que la emigración ha sido selectiva, marchándose los adultos con sus hijos y quedándose los ancianos con menos posibilidades de adquirir una vivienda en otras zonas.

Todos los indicadores demográficos nos señalan las características antes apuntadas; así, la división en grupos de edades, presenta el Cuadro II.

\section{CUADRO II}

\begin{tabular}{|c|c|c|c|c|c|c|}
\hline Año & & $0-14$ & $15-64$ & 65 y más & $\begin{array}{c}\text { Tasa } \\
\text { dependencia }\end{array}$ & $\begin{array}{c}\text { Indice } \\
\text { envejecimiento }\end{array}$ \\
\hline 1821 & ....................... & 36,0 & 59,4 & 4,6 & $68,4 \%$ & 12,8 \\
\hline 1935 & 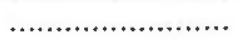 & 26,5 & 68,4 & 5,1 & $46,2 \%$ & 19,2 \\
\hline 1960 & ….................. & 23,0 & 63,6 & 13,4 & $57,2 \%$ & 58,3 \\
\hline 1986 & …......................... & 19,2 & 58,0 & 22,8 & $72,4 \%$ & 118,8 \\
\hline
\end{tabular}



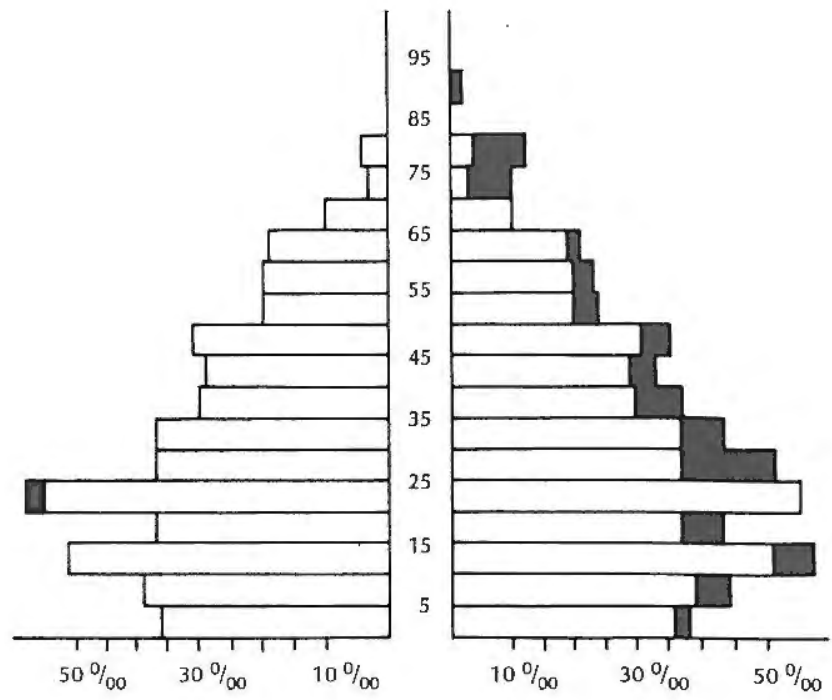

1935
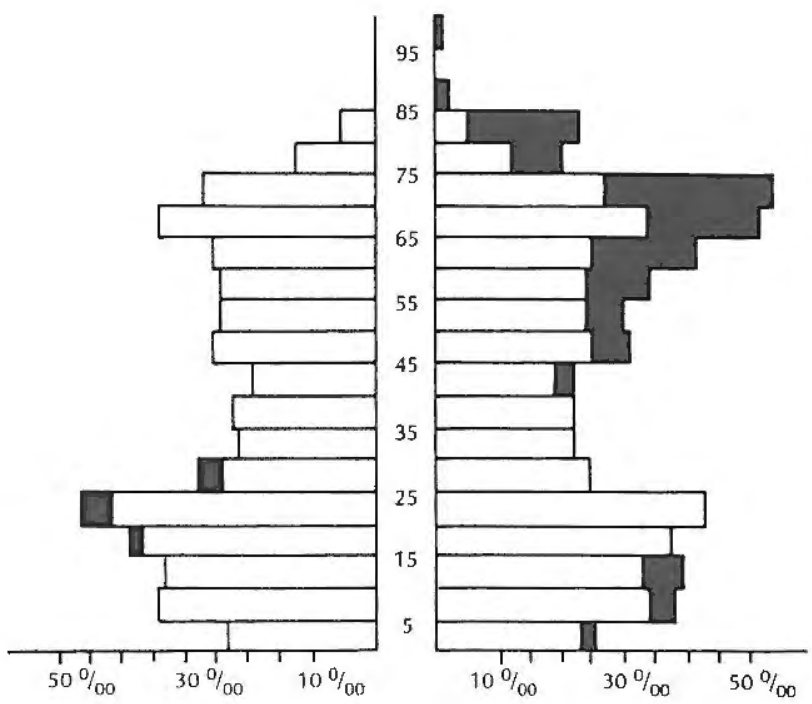

1986

Pirámides de edad, 1935 y 1986. 
La evolución es clara: De una población muy joven en el siglo pasado a una población muy envejecida en la actualidad.

Este proceso ha tenido dos etapas: en la primera, básicamente durante el pasado siglo y el primer tercio del actual, disminuye el número de jóvenes, mientras se incrementa el de adultos, apenas creciendo el de ancianos.

En el último medio siglo, por el contrario, disminuyen los dos primeros grupos, sobre todo el de adultos, aumentando considerablemente el de ancianos, el cual desde 1984-85 ya supera en cantidad al de jóvenes.

El índice de envejecimiento confirma plenamente esta evolución, mientras que la tasa de dependencia muestra una doble tendencia: Los vlaores son muy altos tanto en el siglo pasado como en la actualidad, pero por distintos motivos. En el primer caso, por existencia de un gran número de jóvenes; en el segundo, de muchos ancianos. Sólo en los años correspondientes a mediados del siglo actual, ha existido una población equilibrada con cierto predominio del grupo de adultos.

La caracterización de la población por su edad ofrece estos datos:

\begin{tabular}{|c|c|c|c|c|}
\hline & Año & & Media edad & Mediana \\
\hline \multirow{3}{*}{ - } & 1935 & . & 30 & 27 \\
\hline & 1960 & …............................... & 37 & 34 \\
\hline & 1986 & …1, & 39 & 41 \\
\hline
\end{tabular}

Nota: La moda es poco representativa al tratarse de una muestra de población pequeña.

El proceso de envejecimiento es paulatino, sin altibajos. Se corrobora la hipótesis anterior, ya que en medio siglo la población envejece de menos de 30 años, a tener unos 40 por término medio.

El estudio de la «sex ratio» general o índice de masculinidad presenta estos valores:

Año

1935

1960

1986
Sex Ratio

85,9

77,0

79,7

Crece el número de mujeres (consecuencia lógica del envejecimiento), aunque de una forma irregular. El máximo se alcanza en 1940 con un valor de 89,7; desciende a continuación pero con altibajos hasta llegar al valor actual. Como es normal, en las primeras edades predominan los hombres, para a partir de los 20 ó 30 años ser más numerosas las mujeres. 


\section{ESTADO CIVIL Y COMPOSICION FAMILIAR}

El estudio del estado civil muestra una población con estas características:

\begin{tabular}{lllllc}
\hline Año & & Solteros & Casados & Viudos & $\begin{array}{c}\text { Separados o } \\
\text { divorciados }\end{array}$ \\
\hline 1940 & $\ldots \ldots \ldots \ldots \ldots \ldots \ldots \ldots \ldots \ldots \ldots \ldots \ldots$ & $59,0 \%$ & $33,3 \%$ & $7,7 \%$ & $0,1 \%$ \\
1981 & $\ldots \ldots \ldots \ldots \ldots \ldots \ldots \ldots \ldots \ldots \ldots \ldots \ldots \ldots \ldots \ldots$ & $47,8 \%$ & $41,3 \%$ & $9,2 \%$ & $1,7 \%$ \\
\hline
\end{tabular}

Nota: No ha sido posible recabar los datos de 1986.

Llama la atención la disminución de los solteros, paralela a la de la población en las primeras edades, mientras que crecen los casados y los viudos por el motivo contrario. El aumento de los separados o divorciados está más en consonancia con el cambio general de los hábitos sociales.

Al utilizar sólo el padrón es difícil caracterizar la familia media, pues, lc único que nos permite saber es cuál es el número de personas existentes por cada cabeza de familia. No obstante, este dato es por sí sólo bastante significativo, como vemos a continuación:

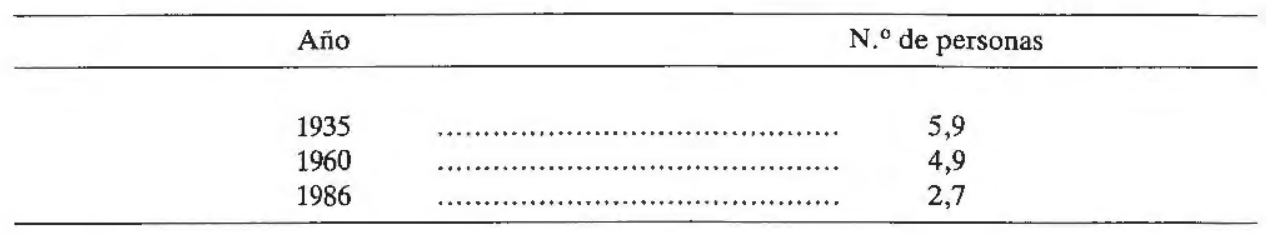

El fenómeno hay que ponerlo en relación no sólo con la disminución de población, y, por tanto con el descenso del tamaño de la familia, sino también con las condiciones de vida existentes, pues revelan un grado de hacinamientc extremo en épocas pasadas, ya que a veces se supera el valor seis.

Téngase en cuenta, además, que incluso se llegaba al caso de dos o más familias en una sola vivienda, con lo cual el problema era aún mayor.

Para completar esta visión sobre las características de la familia, analizare. mos un último dato extraído de los registros de bautismo del archivo parro. quial, como es el del número de hijos naturales. Los resultados son tambiér muy interesantes: 


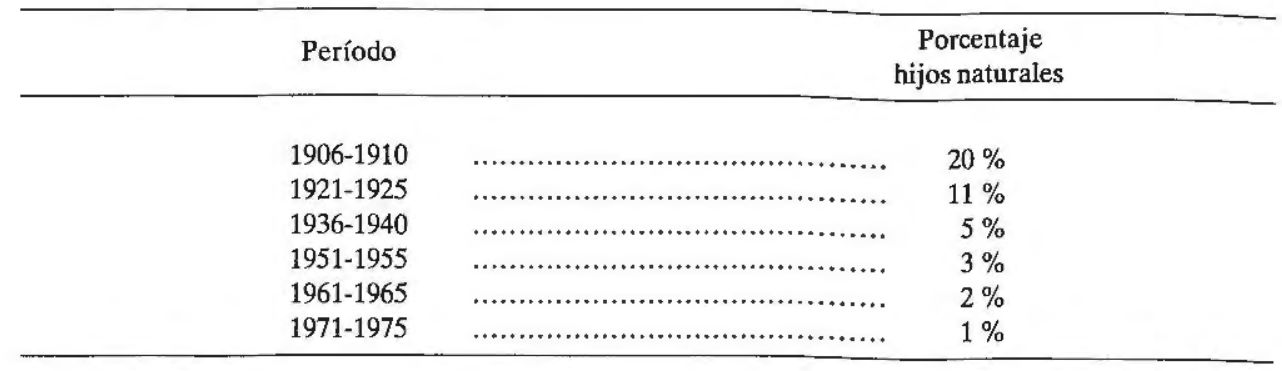

El descenso del porcentaje de los hijos ilegítimos es constante, y en número considerable, ello se debe sin duda a la mejora del nivel de vida, así como indiscutiblemente al empleo de métodos anticonceptivos. Se trata más de un valor con interés psicológico que demográfico en sí, pero que de todas formas contribuye al mejor conocimiento de la población.

\section{CARACTERISTICAS SOCIO-PROFESIONALES}

Hasta mediados del siglo pasado, cuando se produce el derribo de la muralla, San Bernardo era considerado, incluso por sus propios habitantes, como un pueblo de los alrededores de Sevilla. Ello se refleja en una dependencia casi total del sector primario, pues su población se dedicaba básicamente a la agricultura, y en menor escala, a la ganadería. Ha sido, pues, hace un siglo cuando, englobado por la urbe, se han modificado sus estructuras económicas, como se refleja en otros apartados de este trabajo.

Los Cuadros III y IV sintetizan lo antes dicho.

\section{CUADRO III}

TASA DE ACTIVIDAD GLOBAL

\begin{tabular}{|c|c|c|c|c|c|}
\hline Año & & Primario & Secundario & Terciario & $\begin{array}{c}\text { Tasa de } \\
\text { Actividad }\end{array}$ \\
\hline 1821 & 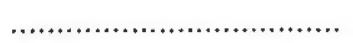 & 22,0 & 7,0 & 0,9 & 29,9 \\
\hline 1935 & 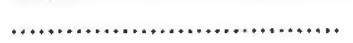 & 8,8 & 14,9 & 6,3 & 30,0 \\
\hline 1981 & 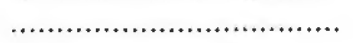 & 1,4 & 15,3 & 9,5 & 23,2 \\
\hline
\end{tabular}




\section{CUADRO IV}

PORCENTAJE DE ACTIVOS POR SECTORES

\begin{tabular}{|c|c|c|c|c|}
\hline Año & & Primario & Secundario & Terciario \\
\hline 1821 & 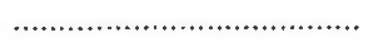 & 73,4 & 23,3 & 3,3 \\
\hline 1935 & 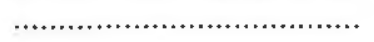 & 29,3 & 49,7 & 21,0 \\
\hline 1981 & 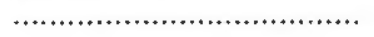 & 5,3 & 58,4 & 36,3 \\
\hline
\end{tabular}

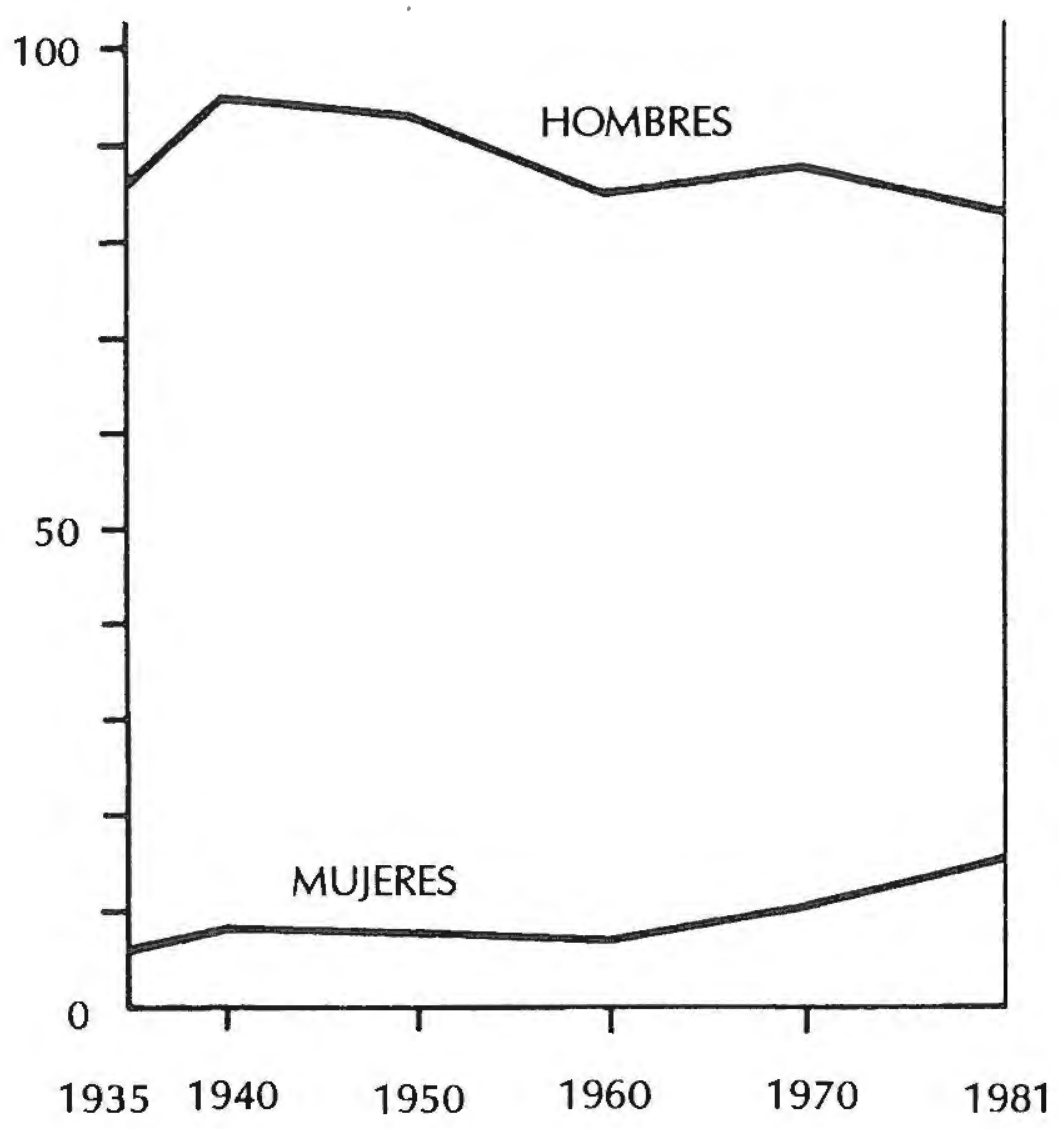

Tasas de actividad, 1935-1981, por sexos. 


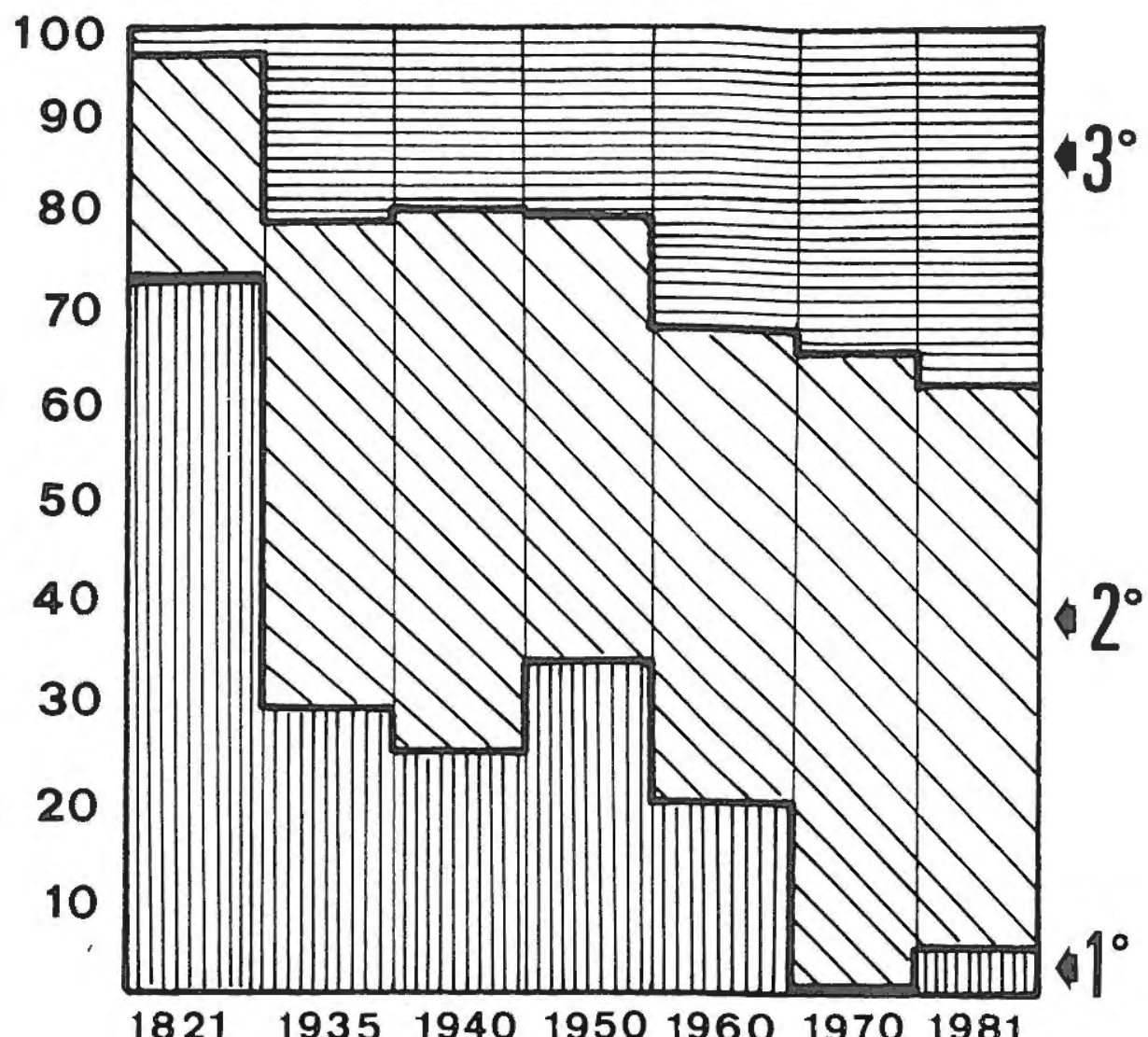

Evolución, 1821-1981, por sectores económicos de la población activa.

Varios comentarios se deducen de lo anterior. En primer lugar, la tasa de actividad es bastante baja (alcanza su máximo en 1940 con 32,8) y además está descendiendo fuertemente a consecuencia del envejecimiento de la población. En segundo lugar, y relativo a los sectores de actividad, se aprecia un cambio importante: De ser una población compuesta mayoritariamente por agricultores en el siglo pasado, se pasa en éste a una población de obreros industriales (recuérdese el auge de la industria desde mediados del XIX). Por el contrario, los últimos datos muestran que, aún sin perder la primacía el sector industrial (fábrica de artillería, talleres de la calle Campamento) se produce un crecimiento muy importante del sector servicios, acorde con la evolución actual de la economía española y, en concreto, y aún en mayor escala, de la sevillana. 


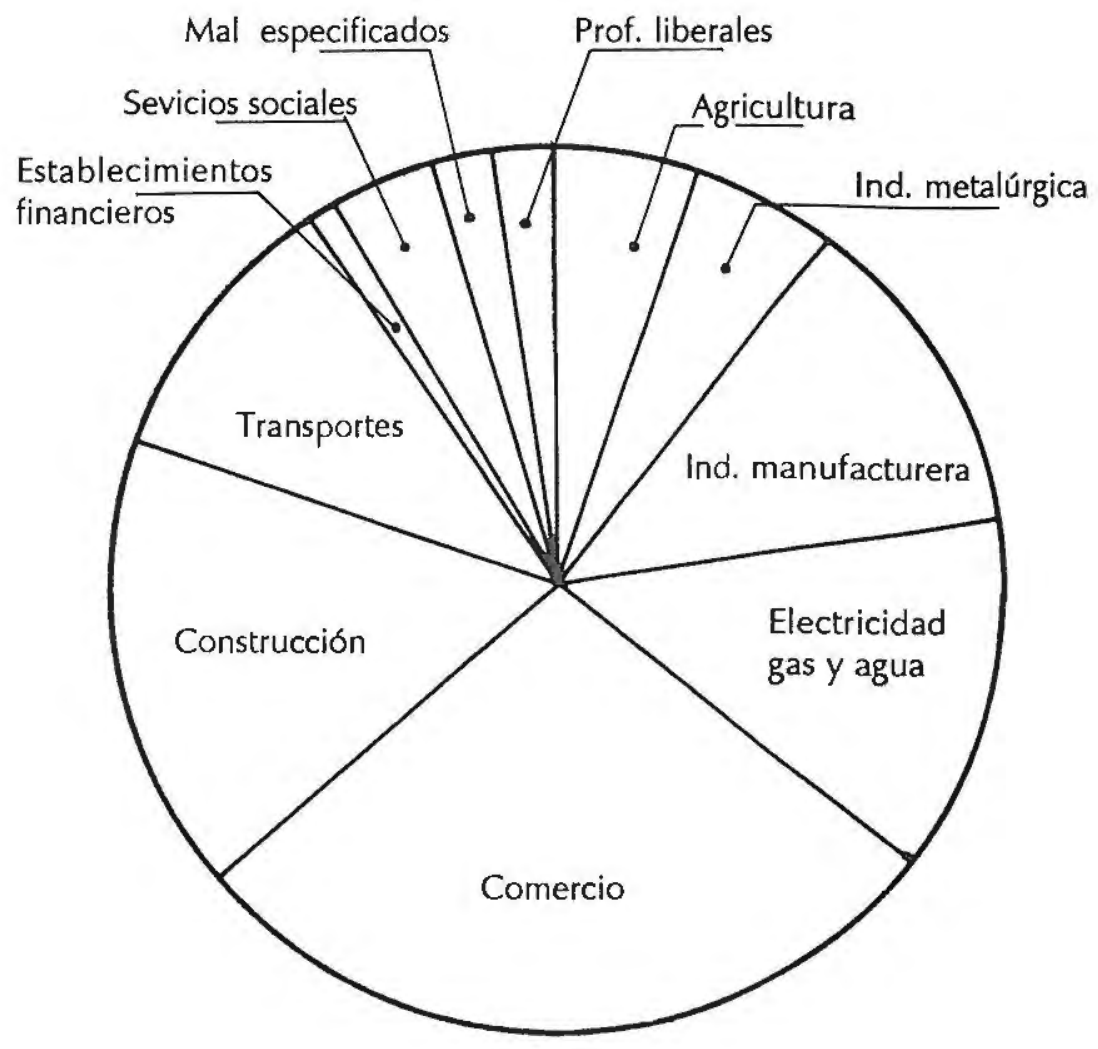

1981

Composición de la población activa por sectores económicos.

Por ramas de actividad, hemos entresado solo aquellas que nos han parecids más significativas (ver Cuadro V).

\section{CUADRO V}


Se observa un cambio muy importante en la actividad de la población, aumentando principalmente dos ramas: construcción debido al alto número de albañiles existentes en el barrio, y comercio, ya que también es importante el número de tiendas y bares que permanecen abiertos a pesar del enorme descenso de la población.

En cuanto a los porcentajes de activos por edades, presentamos los datos comparativos (ver Cuadro VI).

\section{CUADRO VI}

1935

1981

Grupos de edades

10-19

20-29

30-39

40-49

50,59

60-69

70-79

$12,2 \%$

$15,5 \%$

$41,5 \%$

$56,5 \%$

$42,9 \%$

$57,0 \%$

$46,9 \%$

$42,0 \%$

$35,6 \%$

$41,7 \%$

$42,6 \%$

$15,5 \%$

$13,8 \%$

$0,0 \%$

Tasas de actividad por sexo

Varones

$86,8 \%$

$6,3 \%$

$82,9 \%$

Hembras

$14,9 \%$

Por regla general, en la actualidad, la población entra con más edad a trabajar (aunque el dato de 1935 muestre lo contrario, no ocurre lo mismo con el de 1940 ó 1950, probablemente por el alto índice de desempleo en aquel año), y abandona el trabajo antes. Sin embargo, se alcanzan mayores porcentajes de trabajo en las edades intermedias. El mantenimiento de las cifras (incluso a veces con ascensos) en las edades de la madurez, se debe al regreso al trabajo de aquellas mujeres que por haber enviudado necesitan volver a él para su sustento. Los datos hablan por sí sólos de la mejora de las condiciones laborales de los trabajadores, al menos, en una escala general.

De entre los inactivos vamos a referirnos al número de jubilados como representativos del cambio cualitativo de la población. Su porcentaje con respecto al total ha evolucionado así:

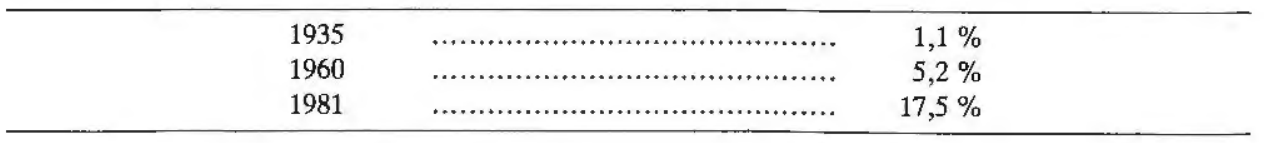


El envejecimiento de la población ha traido como consecuencia un fortísim incremento de los jubilados, junto con un notorio aumento del número de ar cianos (ver Cuadro VII).

\section{CUADRO VII}

\begin{tabular}{|c|c|c|c|}
\hline & Hombres & Mujeres & Total \\
\hline 1. No saben leer ni escribir ............... & 4,4 & 11,4 & 15,8 \\
\hline 2. Primaria incompleta $\ldots \ldots \ldots \ldots \ldots \ldots \ldots . . . . . . .$. & 17,3 & 18,8 & 36,1 \\
\hline 3. Primaria o EGB $1 .^{\circ}$ ciclo $\ldots \ldots \ldots \ldots \ldots$ & 9,0 & 9,3 & 18,3 \\
\hline 4. Bachiller elemental o EGB $2 .^{\circ}$ ciclo... & 2,9 & 2,3 & 5,2 \\
\hline 5. Formación Profesional/Oficialía ..... & 2,0 & 1,0 & 3,0 \\
\hline 6. Bachillerato Superior $\quad$................... & 1,2 & 1,2 & 2,4 \\
\hline 7. Estudiantes de Grado Medio ......... & 0,7 & 0,8 & 1,5 \\
\hline 8. Estudios Superiores & 0,5 & 0,7 & 1,2 \\
\hline
\end{tabular}

De ello se deduce una población escasamente cualificada, con un alto por centaje de analfabetos y semi-analfabetos y una presencia muy reducida $\mathrm{d}$ licenciados universitarios. La diferencia entre sexos es enorme, no en los estu dios más avanzados, sino en los grupos de menor nivel cultural; existe un clara discriminación de la mujer en el acceso a la cultura, que se refleja e un número casi tres veces superior de analfabetas sobre analfabetos.

La evolución del analfabetismo es la que se observa en el Cuadro VII]

\section{CUADRO VIII}

\begin{tabular}{|c|c|c|c|c|c|c|}
\hline \multirow{2}{*}{ Año } & & \multicolumn{3}{|c|}{ Sobre el total de población } & \multicolumn{2}{|c|}{ Sobre total de cada sexo } \\
\hline & & $\mathrm{V}$ & $\mathrm{H}$ & Total & V & $\mathrm{H}$ \\
\hline 1935 & 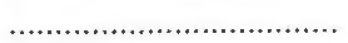 & 9,8 & 19,8 & 29,6 & 21,2 & 36,8 \\
\hline 1960 & 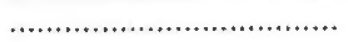 & 5,9 & 14,0 & 19,9 & 13,6 & 24,8 \\
\hline 1981 & 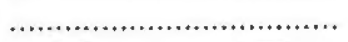 & 4,4 & 11,4 & 15,8 & 9,6 & 21,0 \\
\hline
\end{tabular}

El descenso es continuo, aunque bastante lento, seguramente debido a cau sa de la estructura envejecida de la población, el hecho de que el analfabetis mo sea más frecuente entre las personas de mayor edad, las más numerosa en el total, abona esta opinión. Sigue observándose una importante diferenci. entre ambos sexos, que se va reduciendo, aunque muy lentamente. Hay qu tener en cuenta una ligera subida de las tasas entre 1970 y 1981, de 13,8 : 15,8 , a consecuencia del empadronamiento en el último año de numerosas fa milias gitanas recién llegadas al barrio y de muy bajo nivel cultural. 


\section{MOVIMIENTOS MIGRATORIOS}

Teniendo como única fuente de estudio el padrón, bién poco se puede analizar en este sentido, ya que lo único que se puede conocer con total fiabilidad es la procedencia de los inmigrantes, la importancia en número de los mismos y escasos datos referidos a la composición de este grupo.

El porcentaje de inmigrantes con respecto al total de población, evoluciona del siguiente modo:

1935

1960

1981
$38,8 \%$

$36,2 \%$

$33,6 \%$

Es decir, cada vez es menor el número de foráneos. Algo lógico, ya que el barrio ofrece pocos atractivos para la inmigración, y, por el contrario, sólo permanecen las personas mayores que rara vez suelen formar parte de los procesos migratorios.

Sus lugares de procedencia son heterogéneos. En primer lugar, de los pueblos de la provincia próximos a Sevilla (Osuna, Utrera, etc.), seguidos de la provincia de Cádiz (y en concreto de Jerez), Huelva y Málaga, siendo el resto en su mayor parte de las restantes provincias de Andalucía o Extremadura.

El nivel educativo de los foráneos es sensiblemente superior al de los autóctonos. Ello se mantiene constante desde 1935 hasta la actualidad y no parece que ocurra porque los inmigrantes sean especialmente cultos sino, por el contrario, porque el uivel de los nacidos en el barrio (o en Sevilla) es bastante bajo.

En cualquier caso, y siguiendo la pauta normal, los inmigrantes deben de ocupar por regla general mejores puestos laborales que los nacidos en Sevilla.

\section{ASPECTOS URBANISTICOS}

No se ha pretendido realizar en ningún caso un estudio exhaustivo desde el punto de vista urbano, sino solo complementar las características demográficas con el conocimiento del marco urbano en que se inscriben.

La evolución urbana es en gran medida correlativa a la demográfica, aunque, como ya antes señalamos, no tienen por qué tener necesariamente un nexo de unión total. La forma de estudiarla es acudir a aquellos planos que indiquen el estado de la zona en diferentes épocas, o bien recurrir a fuentes escritas que hagan referencia a este asunto las cuales, en este caso, desgraciadamente son bastante escasas. 
En cuanto a la cartografía tampoco es especialmente abundante, principal mente porque al estar situado San Bernardo extramuros de la ciudad, no e reflejado en los planos más antiguos (como el de Olavide) al no ser conside rado como parte integrante de Sevilla.

Según las figuras de los planos que presentamos, la evolución urbana pode mos sintetizarla de este modo:

Ya señalamos cómo el barrio surge a finales del siglo XV o comienzos de XVI en torno a la ermita de San Bernardo, y como lugar de residencia de lo trabajadores de la Huerta del Rey. Nada sabemos de la estructura de este pri mer núcleo, puesto que ninguna fuente que describa al mismo nos ha queda do; cierto que Hoefnagle en su grabado de 1565 ya situa algunas casas en 1: zona, y que del siglo XVIII conservamos planos de la antigua fundición y di la Huerta del Rey, pero al no aparecer en el plano de Olavide no tenemo constancia fidedigna del conjunto hasta 1826, gracias al plano de Manuel di Spínola.

La hipótesis que se presenta parte de la base de un plano original octogona compuesto por 14 manzanas, 10 centrales simétricas, pero con distinta super ficie, y otras cuatro que rodean por dos lados al núcleo central. Por motivo que desconocemos no se ocupó todo el cuadrante Noreste, quedando el planı tal y como se muestra en la figura $\mathrm{B}$, desapareciendo una de las manzana rectangulares.

En el siglo XVIII se introduce un nuevo elemento, como es la fábrica d artillería, que modifica la estructura existente hasta entonces, como se mues tra en la figura $C$, ya que sabemos que la fábrica se construyó a expensas d، ocupar varias manzanas de casas existentes hasta entonces. Aún hoy se obser va en su interior (línea discontínua) el trazado de la antigua calle, que ho: recorre la parte central de este edificio.

La figura D nos muestra el resto de la evolución hasta llegar aproximada mente a la morfología actual del San Bernardo tradicional. Hay que destaca el hecho de que las líneas discontinuas muestran aquellas alineaciones del par celario que aún se conservan como pervivencia de lo que probablemente debic ser la primitiva estructura urbana del barrio.

Encajado entre el arroyo Tagarete y los límites de la Huerta del Rey, Sa Bernardo crece hacia la única área de expansión que tiene: la prolongació 1 de la calle Ancha, llamada hoy Campamento. El crecimiento durante el siglc XIX va a ser lento pero constante, y así lo señalan los diferentes planos dt la época (Arjona, Sartoriuos, Alvarez Benavides). Hasta 1850, el barrio siguধ 
casi centrado en su núcleo tradicional, pero cuatro hechos decisivos: el derribo de la muralla, el cubrimiento del arroyo Tagarete, el surgimiento de industrias en los alrededores y, sobre todo, la creación de la estación de ferrocarril, van a motivar la ocupación del espacio vacante que esta última deja entre ella y la Huerta del Rey, constriñendo al barrio de una manera total, modificando sus límites tradicionales y encajándolo de una forma caprichosa en su expansión.
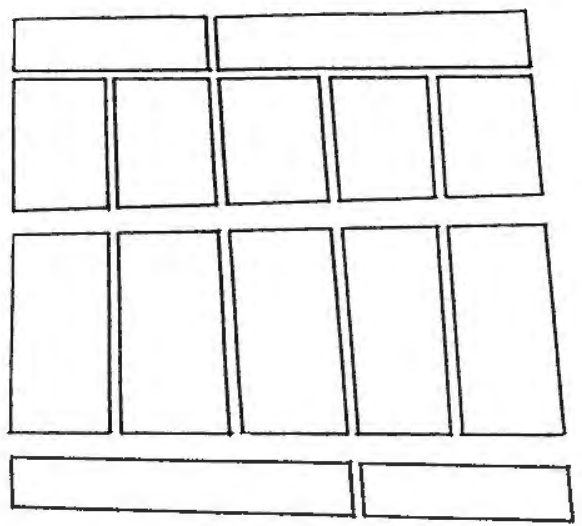

FIG. A

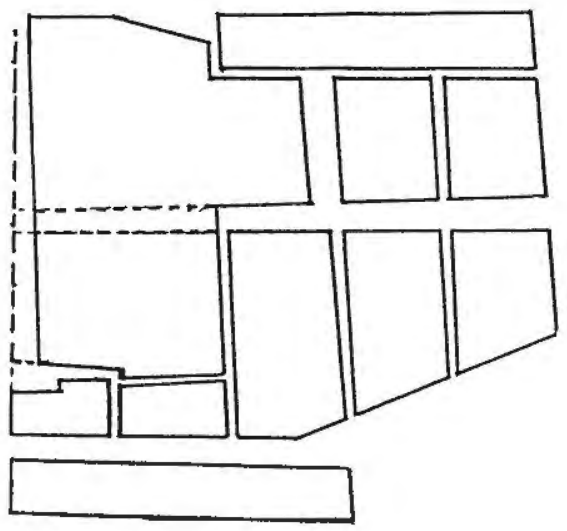

FIG. C

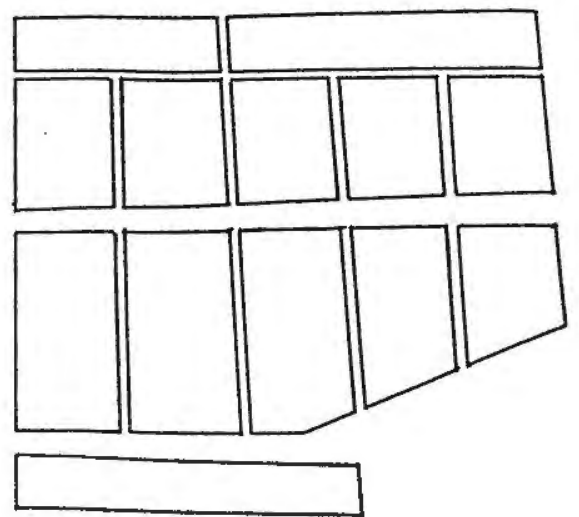

FIG. $B$

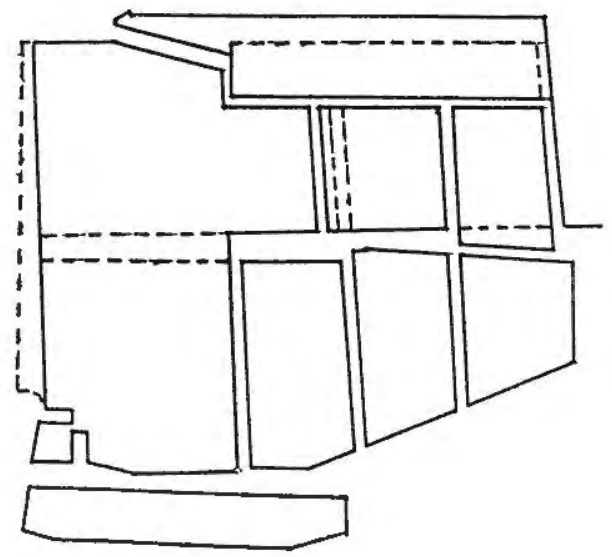

FIG. D

Origen y formación del Barrio de San Bernardo. 


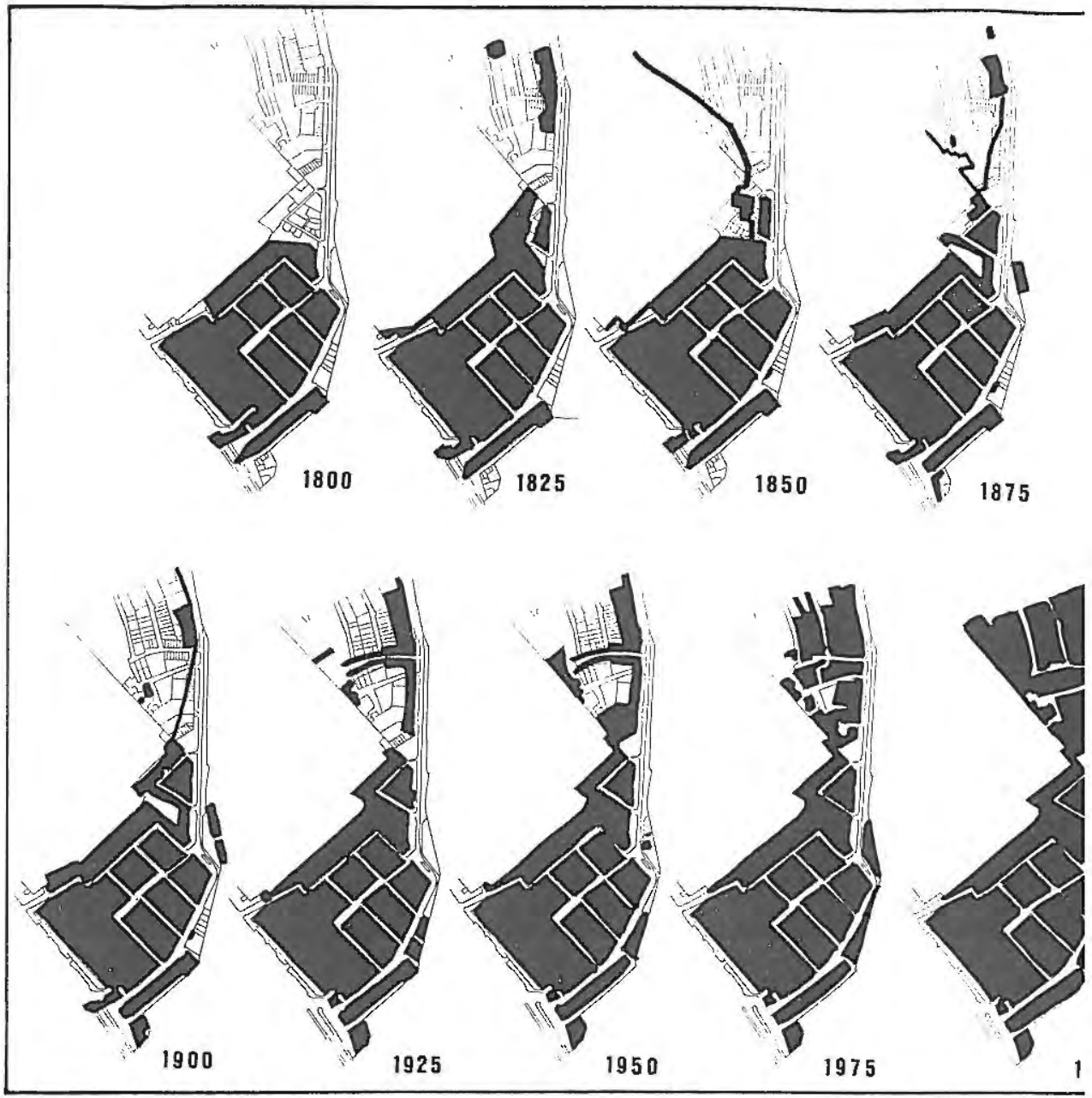

Evolución del Barrio de San Bernardo, 1800-1988.

El último gran momento constructivo llega en los finales del siglo XIX, J sobre todo a principios del XX; en que se parcela este espacio vacío, surgier do en primer lugar las calles Huestes y Valme, ya con el diseño actual, y pos teriormente, hacia 1910, la calle Barrau, que supone una operación urbaníst ca singular y homogénea dentro del caos en que se produce este crecimientc generando una oferta de vivienda barata unifamiliar. 
La ocupación del espacio posterior a la calle Campamento no se produce hasta mediados de este siglo, en que surgen de forma totalmente anárquica una serie de construcciones de baja calidad, que son utilizadas como talleres y almacenes, y que hoy día configuran la parte oculta y degradada del San Bernardo más reciente.

De todo este proceso se genera un plano con una morfología peculiar. San Bernardo se nos presenta conformado por dos grandes triángulos unidos por uno de sus vértices, en los cuales quedan perfectamente definidos el San Bernardo tradicional y la zona de nuevo crecimiento desde el siglo pasado.

En contraposición, la zona más antigua presenta una mayor regularidad tal y como apuntábamos antes, mientras que el área de ensanche se vertebra básicamente a lo largo del eje que forma la calle Campamento, adaptándose a las formas de los muros de la Huerta del Rey y del ferrocarril. Es este último espacio anárquico en su concepción. En su primer tramo continuan las viviendas por su proximidad al San Bernardo tradicional, pero la peculiar disposición de la tapia que aisla a la Huerta del Rey, propicia una serie de extrañas inflexiones, que traen como consecuencia manzanas o espacios triangulares no muy habituales en el urbanismo sevillano.

La zona más próxima a la Avenida de Ramón y Cajal presenta una disposición totalmente caótica y desordenada. Los talleres, almacenes, etc. han surgido sin orden preestablecido, apareciendo frecuentes callejones sin salida, calles de trazado quebrado, escasa rectilineidad, etc. y todo ello sin hablar de la casi total ausencia de dotaciones, comenzando por la más básica de ellas, pues el viario está sin asfaltar ni adoquinar en su mayor parte, existiendo a modo de caminos de tierra que se convierten en un lodazal con la lluvia. Es la parte oculta del barrio, situada por lo demás, recordémoslo, casi en pleno centro geométrico de la ciudad.

Actualmente puede decirse que se está iniciando en el edificado una ligera fase de transición hacia su recuperación. La realidad es que el estado que presenta el mismo es de auténtica ruina en la mayor parte de las construcciones; ello obedece a que gran parte de las viviendas fueron levantadas a finales del siglo pasado, e incluso se conservan aún varias del siglo XVIII, siendo muy pocos los edificios construidos desde 1960 hasta hoy, si exceptuamos la reciente promoción de viviendas de la Cooperativa. En la zona de la calle Campamento, la edad de la edificación es algo menor, pero también predominan las construidas durante la primera mitad de siglo.

Según las alturas del edificado, el tipo de casa más habitual es la de dos plantas. Las casas de una planta se localizan en las calles Barrau y Campamento, mientras que las de tres pertenecen por regla general a los edificios más recientes. 
Tipológicamente encontramos cinco grupos de casas: unifamiliar, de un sola planta (las ya mencionadas en Barrau y Campamento); la casa-patio d dos plantas (la más genuina y de la que quedan aún magníficos ejemplos e la calle Santo Rey) la casa de vecinos de varias plantas (en las zonas periférice del barrio); el corral de vecinos (lo más habitual hasta el siglo XIX según c estudio del Dr. Hauser y, los pocos que quedan hoy en estado de total ruina' y por último, las casas de varios pisos (los bloques) de nueva construcció (existen pocos por los condicionantes ya indicados).

Entre el mobiliario urbano cabe destacar: los botarruedas, rótulos peculi res («Hay vecinos», en las pocas casas habitadas, «calle particular», cerrada con una verja). Los bancos son escasísimos, el arbolado sólo abunda en 1 calle Campamento, las fuentes desaparecieron a principios de siglo, las farola son contadas, salvo en la calle Campamento y San Bernardo.

El estudio del viario ha de realizarse en estos dos apartados: a) Estructur interna; b) Comunicaciones con el resto de la ciudad.

En el primero, nos encontramos con un gran eje que atraviesa longitudina: mente todo el barrio formado por la calle San Bernardo y la calle Campamer to. Es la vía más rectilínea y de mayor anchura. El resto de las calles sigue este trazado recto pero son notablemente más estrechas. En la zona más rє ciente se pierde esta rectilineidad, unida además a la falta de una pavimenta ción adecuada. No existen las calles peatonales, aunque en algunos casos $\epsilon$ tráfico rodado es prácticamente imposible por la estrechez del viario (con fluencia entre Portacoeli y Marqués de Estella).

El segundo aspecto motiva el que San Bernardo sea un barrio cerrado aislado con respecto a la ciudad. Las dos grandes arterias que lo delimitan Eduardo Dato y Ramón y Cajal, no tienen adecuadamente resueltas las cone xiones con las del interior de la zona, pese a la reciente mejora de la últim de ellas. El pasadizo subterráneo bajo las vias del ferrocarril facilita la comu nicación a pié con el centro urbano, pero por sus propias características nı es muy utilizado debido a los problemas de inseguridad ciudadana. Los do puentes, Enramadilla y San Bernardo, son las otras dos vías de acceso peato nal al casco antiguo, aún con las molestias que conllevan.

Los transportes urbanos sólo sirven los alrededores del barrio en las do grandes vías ya mencionadas. Debido a la despoblación, no existen problema de aparcamiento, aunque ante una posible reactivación pudieran surgir por li poca adecuación del viario a este aspecto. El tráfico interno es muy escasc pero la disposición estrecha de las calles planteará dificultades cuando comien ce de nuevo a poblarse la zona. 
Los espacios libres son poco numerosos; no existen las zonas verdes, lo mismo puede decirse de las plazas, aunque esta función pudiera adjudicarse a la calle Almonacid por su ensanchamiento junto a la Parroquia, o también a la confluencia entre las calles San Bernardo y Campamento, en el punto más estrecho, donde queda aislada en el centro del viario una «isla peatonal».

Quedan espacios vacantes entre las calles Huestes y Campamento por el desordenado crecimiento urbano, así como en el área entre la Calle Campamento y la Huerta del Rey, aprovechados estos últimos como vertedero o bien como campo de futbol, pero son lugares poco significativos dentro de todo el conjunto.

La dotación de servicios e infraestructuras es por regla general escasa, aunque más correcto sería calificarla de desequilibrada, pues en algunos aspectos el barrio está muy bien servido, como por ejemplo en el docente, gracias a los esfuerzos de la parroquia, y en otros es casi nulo: el cultural, o el sanitario. La red de agua, electricidad y alumbrado no es muy buena, pero ante la limitada demanda que se genera, puede considerarse como suficiente.

Para finalizar los aspectos urbanos hay que hacer referencia a uno de los temas que han frenado más decisivamente el porvenir del barrio, como es el urbanístico.

Los problemas comienzan en 1960, cuando el Consejo de Ministros declara el barrio zona comercial. Se inicia con ello un proceso de especulación en el precio del suelo. La congelación de licencias para viviendas impide que se realicen nuevas construcciones, lo que, unido al año siguiente a la inundación del Tamarguillo, provoca la ruina del edificado.

En 1962 el PGOU, por el contrario califica a la zona como suelo de edificación tipo intensivo-alta, pero en 1963 se rectifica el contenido del Plan General, modificando de nuevo su uso como reserva para el futuro centro comercial de la ciudad dentro de las características del desarrollismo imperante en la época. Con ello entraba otra vez en vigor la prohibición para conceder licencias de construcción.

En los cinco años siguientes, el proyecto de zona comercial va perdiendo justificación ante el surgimiento de grandes almacenes en el centro de la ciudad (Plaza del Duque, Plaza de la Magdalena), y el auge comercial del barrio de los Remedios. Pese a ello, todavía en 1969 el arquitecto Morales Lupíañez presenta un nuevo plan, el último, para la transformación de San Bernardo en zona comercial.

La inviabilidad de dicho proyecto era evidente ante la situación del momento. En otra línea más acorde con las circunstancias del barrio se crea, a fines de 1968, por iniciativa del párroco José Alvarez una Cooperativa de viviendas entre los vecinos del barrio para reactivar la reconstrucción del caserio. Motivos de diversa índole retrasarán 15 años los proyectos de la Cooperativa. 
En 1970 se realiza un Plan Especial para la ordenación del sector, cuyos dos puntos básicos son: El abandono del proyecto comercial y la concesión de licencias para la construcción. En 1971 se aprueba, pero la Cooperativa consigue que se detenga la concesión de licencias de obras, al estar en desacuerdo con el tipo de viviendas que se proponían.

En 1972 se intenta aplicar un nuevo proyecto de reforma interior (un miniPRICA), pretendiendo construir un elevado número de viviendas en torno a] futuro eje Norte-Sur que atravesase los jardines de la antigua Buhayra. El proyecto prevía que se duplicase la población del barrio, pero de nuevo trabas burocráticas y administrativas impiden que se lleve a la práctica.

Nuevos planes y proyectos realizados entre 1977 y 1979 por empresas privadas (OTAISA) y particulares, para la reactivación de la zona, tampoco alcan. zan los fines propuestos, aunque son muestra evidente del interés que suscita el asunto.

La situación permanece diez años estancada. El choque de intereses entre la Comisión Provincial de Urbanismo y los propietarios de viviendas de la Cooperativa, provoca el acrecentamiento de la ruina del caserio, al que se une desde 1980 los efectos negativos de las obras del Metro.

En 1982 se abre una nueva etapa con la aprobación del avance de las Normas Complementarias de San Bernardo. Al año siguiente el Instituto de Promoción Pública de la Vivienda intenta construir junto con el Patronato Municipal de la Vivienda, 123 viviendas, pero las condiciones que plantea la Cooperativa (tras fuertes disensiones internas) para ceder el suelo no son aceptadas por el Patronato y el proyecto fracasa una vez más.

En el mismo 1983 son aprobados definitivamente las Normas Complementarias. En 1984 el Patronato intenta por segunda vez comprar terreno, dirigiéndose en este caso a los particulares que no estén en la Cooperativa. E] tropiezo ahora es una gran escasez de suelo disponible, ante lo cual renuncia definitivamente a seguir intentándolo.

A fines de 1984, la Cooperativa consigue la concesión de licencia municipal de obras e inmediatamente inicia la construcción de 29 viviendas, que, a mediados del siguiente año, son puestas a la venta.

En 1986 se inicia una segunda fase de construcción más numerosa con la que se pretende el resurgimiento del barrio.

Por último, en 1987 se realiza la revisión del PGOU, que supondrá cuando se lleve a cabo una enorme modificación de San Bernardo en los próximos cinco años. Fundamentalmente se plantean en él tres hechos:

- La desaparición de todo el complejo de la estación de ferrocarril, y la construcción de un apeadero subterráneo, con lo que se romperá el permanente aislamiento de la zona. 
- La conservación de la parte tradicional, intentando su mantenimiento en los casos en que sea posible, y renovando sólo aquellos casos de ruina irreversible, siguiendo las pautas urbanísticas del entorno.

- La transformación total de la zona nueva en la Calle Campamento con la casi total eliminación de todo lo que existe hoy, y proyectando nuevas viviendas, siguiendo un plano cuadriculado, con un viario de anchura considerable, recuperando la Huerta del Rey como zona verde para ser utilizada por los nuevos vecinos.

\section{CONCLUSIONES}

San Bernardo es un barrio en el que la Historia ha condicionado decisivamente su situación actual (estación del ferrocarril, Huerta del Rey, etc.). El nexo entre población y urbanismo es muy importante, siendo paralelo el declive de la primera cuando los condicionantes urbanos (ruina del edificado) entran en decadencia.

La crisis es coincidente con la época de despegue y apogeo de Sevilla, cuando a fines de los años 50 y principios de los 60 se inicia la gran expansión propiciada por los años del desarrollo; se produce, por el contrario, el período de degradación del barrio, que no puede o, mejor dicho, al que no dejan engacharse al tren que a partir del aquel momento sigue la ciudad.

Las circunstancias concretas que concurren en este caso, pero especialmente una serie de medidas desacertadas en materia de política urbanística, provocan un profunda crisis que alcanza su punto más bajo a mediados de la presente década en la que parece que por fin, se abre un nuevo período en el acontecer de San Bernardo, con la construcción a gran escala de viviendas que permitan la reactivación de la zona.

El nuevo planteamiento prevé perspectivas halagueñas para un barrio que jamás debió haber sufrido el abandono de que ha sido y, todavía es, objeto.

\section{FUENTES}

DELEGACION MUNICIPAL DE ESTADISTICA DE SEVILLA: Padrones Municipales de los años 1935, 1940, 1950, 1955, 1960, 1965, 1970, 1975, 1981, 1986.

ARCHIVO DUCAL DE MEDINACELI: Sección Huerta del Rey.

ARCHIVO PARROQUIAL DE SAN BERNARDO: Libros de Bautismos, Matrimonios y defunciones.

PLAN GENERAL MUNICIPAL DE ORDENACION URBANA: Documento de aprobación provisional. Memoria de propuesta. Sevilla, 1987.

Otros planes de ordenamiento. 


\section{BIBLIOGRAFIA}

ALMOGUERA SALLENT, P.: La Barriada de los Pajaritos. Biblioteca de temas sevillanos, n. ${ }^{\circ} 12$ Sevilla, 1981.

ALVAREZ SANTALO, L.C.: La población de Sevilla en el primer tercio del siglo XIX. Diputaciór provicial de Sevilla.

CRUZ VILLALON, J.: (Coordinadora) La población de Sevilla. Biblioteca de temas sevillanos n. ${ }^{\circ} 33$. Sevilla, 1986.

GARCIA BAQUERO, G.: El fenómeno de la muerte en la parroquia de San Bemardo de Sevilla (Separata).

GOMEZ ZARZUELA, M.: Guía de Sevilla y su provincia. Del n. ${ }^{\circ} 1$ al n. ${ }^{\circ} 59$ (año 1957). 